\title{
Alberto Manguel \\ El viajero, la torre y la larva: el lector como metáfora.
}

Buenos Aires: FDCE, 2015. 129 p. ISBN 978-987-719-075-5

Alberto Manguel, actual director de la Biblioteca Nacional de la Argentina, ha residido en muchos países. Ciudadano canadiense, es editor, traductor y autor de libros muy conocidos como Una historia de la lectura, de 1996. Escribe, sobre todo, en inglés $y$, menos, en español.

Este libro puede considerarse una reflexión posterior a Una historia de la lectura. Desde el título, el autor anuncia sus tres teorías del lector como metáfora: el viajero, la torre y la larva. El texto se estructura en una introducción, tres capítulos -que explican cada una de las formas propuestas por Manguel de esa metáfora del lector-, una conclusión de sugestivo título "Leer para vivir”, agradecimientos e índice analítico. Hay que agregar que el libro posee hermosas ilustraciones de ejemplares únicos de arte antiguo.

La introducción comienza con una frase profundamente certera: "Hasta donde sabemos, somos la única especie para la que el mundo parece estar compuesto de historias". Justifica, en las limitaciones que posee la lengua para explicar el mundo, el uso de las metáforas. Según el autor, estas muestran que la lengua es incapaz de comunicar directamente. Cuenta que las sociedades literarias crearon la noción del mundo como un libro al que se puede leer e interpretar. El lector sería, entonces, un viajero que avanza por las páginas. La metáfora de la torre se refiere a la torre de marfil del lector, que pretende deslindarse de los problemas del mundo. Por último, la metáfora de la larva se refiere al lector que "devora" los libros ("ratón de biblioteca" se le dice habitualmente). Frente a la repetida cuestión de la desaparición del libro a causa del avance de las nuevas tecnologías, Manguel piensa que lo importante es centrarse en lo que no cambia en el acto de leer, en el vocabulario que desplegamos, como seres autoconscientes, en la constante persecución de la imaginación y de la esperanza.

El primer capítulo, cuyo título es "El lector como viajero: la lectura como reconocimiento del mundo", aborda la primera de las tres metáforas sobre el lector postuladas por Manguel.

El libro es muchas cosas. Un receptáculo de la memoria, un medio para superar las limitantes del tiempo y del espacio, un lugar para la reflexión y para la creatividad, un archivo de nuestra experiencia y la de los otros, una fuente de felicidad, de iluminación y, en ocasiones, de consuelo, una crónica de eventos pasados, presentes y futuros, un espejo, un compañero, un maestro, una convocatoria de los muertos, un divertimento; el libro en sus muchas encarnaciones, de la tableta de arcilla a la página electrónica, ha servido por mucho tiempo como una metáfora de muchos de nuestros conceptos y empresas esenciales (p. 18).

La cita extensa intenta definir lo indefinible: la compleja esencia del libro, encarnado en todas sus formas posibles. La tradición judía fijó la idea del mundo como libro, al tratar de entender el sentido del hombre y 
de la vida como camino en un libro escrito por Dios: la Biblia. Leer es una actividad, es un viaje. La misma Biblia narra el peregrinar del pueblo hebreo hacia la Tierra Prometida. Las páginas leídas quedan en el pasado, la página del presente es la lectura que se deshilvana en las manos del lector y las páginas por leer, el futuro incierto. El lector como viajero es el lector que peregrina por su vida como se lee un libro.

Durante todo el texto, Manguel le habla a un lector modelo que ha de manejar una enciclopedia inmensa, como diría Umberto Eco. Los conocimientos variados, exóticos, profundos, invitan a pensar en Borges pero sin la ficción. No en vano Manguel fue amigo personal del escritor argentino y ahora uno de sus sucesores en el cargo de director de la Biblioteca Nacional. Manguel, como Borges, cita a grandes clásicos, a escritores olvidados por las generaciones, a libros perdidos en la memoria de los tiempos, con una naturalidad sorprendente y su prosa fluye lúcida y transparente para un lector curioso pero de alto respeto por la cultura humanista.

Al partir de la noción de que peregrinar incluye la ida al santuario pero también su regreso, Manguel toma como modelo la Divina comedia y entiende que el viaje por la lectura es un viaje que incluye el retorno. Los lectores viajeros pueden ser recompensados con alegrías y satisfacciones o castigados con tristezas y frustraciones. No es el viaje de ida el que dará al lector el entendimiento sino el de regreso, afirma. Siguiendo las ideas de San Agustín y de San Buenaventura, entiende que el viaje también puede ser solamente un camino de preparación para lo que vendrá después.

Cuando Manguel compara el viaje por la lectura en papel con el viaje por la lectura digital - aunque aclara que uno no es mejor que el otro sino que son diferentes- no puede dejar de ocultar sus preferencias. El papel le abre al lector un camino ilimitado que solo él puede recorrer. El libro digital, en cambio, lo conduce, mediante los enlaces, a un recorrido turístico preparado por otros. Asevera:

Ahora debemos volver a aprender a leer lentamente, de manera profunda y abarcadora, ya sea sobre el papel o la pantalla: para viajar con el fin de regresar con lo que hemos leído. Solo, entonces, en el sentido más profundo, seremos capaces de llamarnos lectores (p. 55).

El segundo capítulo se titula "El lector en la torre de marfil: la lectura como alienación del mundo". Libre de meditar, de contemplar en profundidad, el lector en su torre puede caer en una suerte de acedia, de pereza que lo lleve a desentenderse del mundo real. La biblioteca personal en una casa, un lugar de estudio o de soledad, era para Montaigne el principio de la felicidad. Recordamos inmediatamente la reivindicación para las mujeres de Virginia Woolf en Un cuarto propio. Un espacio de soledad, de recogimiento, respetado por todos los habitantes de la casa y necesario para acceder a la lectura y a la profundidad del pensamiento. El término literal "torre de marfil" apareció en el siglo XIX no con una connotación negativa como tuvo después, sino como una metáfora de un espacio de lectura y de reflexión necesario para el intelectual. Pero muy pronto esa metáfora se transformó en una forma despectiva de aquel que se aleja de los problemas del mundo, que no se compromete con la vida de la sociedad o con la cultura de masas.

Para San Agustín, según Manguel, el paso de las palabras leídas al entendimiento 
del resto de los hombres es esencial. Se lee y medita para enseñar a los demás lo valioso que las páginas encierran. $\mathrm{Al}$ citar a Borges, el autor recuerda que el escritor argentino describió el hecho estético como "la inminencia de una revelación, que no se produce". Así, la torre de marfil se convierte en una sala de espera, intolerable para la mayoría de los seres humanos.

Sin embargo, grandes intelectuales como Santo Tomás reclamaron la necesidad de ese espacio de soledad y silencio como lugar privilegiado para la fructificación de las ideas. El capítulo se cierra con una referencia a la obra "apocalíptica" de Nicholas Carr y Manguel vuelve a criticar negativamente la vida "online" como una existencia de distracción permanente que impide la reclusión para profundizar el pensamiento humano.

El tercero y último capítulo lleva la denominación de "La larva de los libros: el lector como inventor del mundo" y se refiere a la tercera metáfora propuesta por el autor para la noción de lector. El concepto de "larva de los libros" alude a un lector voraz, que se alimenta insaciablemente de la lectura y se encierra en un mundo de libros. Para referirse al contrato entre escritor y lector, Manguel acude a dos autores: Umberto Eco, en Los límites de la interpretación, y Bruno Bettelheim, en Psicoanálisis de los cuentos de hadas. Ese contrato de lectura, podríamos afirmar, se basa en un "como si". Los niños escuchan "Blancanieves" como si el mundo posible del cuento fuera el mundo real, aunque saben bien que no lo es. El escritor que termina su libro y el lector que comienza a leerlo posee "el deseo de que lo que dice la página sea cierto y la creencia en que no lo es". Esa tensión entre el escepticismo y la confianza se relaciona directamente con lo que Eco llamó los "límites de la interpretación", sostiene Manguel.

No obstante, la mayoría de los lectores ha sentido alguna vez que se enamoró de un personaje, que el mundo descripto existe realmente, que vivir allí podría ser maravilloso. Inmediatamente se piensa en la Tierra Media de Tolkien. ¿Puede no existir en el mundo real? Manguel cree que este sentimiento es el que lleva a la estigmatización de este tipo de lectores en la figura de "el necio de los libros". Aquellas personas a las que se les dice que dejen la lectura y salgan a vivir. Como si la lectura no fuera vida también. El necio de los libros puede verse también como un lector omnívoro que confunde cantidad con calidad, que cree que sumar libros a su biblioteca es sumar conocimiento de forma instantánea. Es el que se traga las palabras sin apropiarse de su significado. Manguel conjetura que muchas de las visiones estereotipadas del lector asiduo como "tonto" o que no está preparado para la vida o como cobarde que se evade de ella, tienen que ver con el miedo a la palabra. Lo que se ingiere en la lectura luego ha de ser hablado. Ese es el temor de las mayorías. Y pone énfasis: "no pueden eliminar la capacidad humana de imaginar el mundo a través de la lengua".

Don Quijote, para Manguel, supera el concepto de "el necio de los libros". Su "locura" de creer en verdaderos los relatos de ficción lo impulsa a salir al mundo a cuestionar y a enfrentar los valores hipócritas de su época. El caminar de Don Quijote denuncia una sociedad que se burla del que persigue el bien y la verdad. Este último capítulo se cierra con estas reflexiones y el escritor no 
retoma, como en los dos anteriores, el tema de la lectura digital.

Finalmente, las conclusiones se llaman significativamente "Leer para vivir". La frase pertenece a Flaubert, quien se consideraba a sí mismo un lector viajero. Aquí Manguel analiza los personajes de ficción lectores, como Emma Bovary o Ana Karenina. Recurriendo a Platón, el autor se pregunta por qué la representación puede atraer más que la realidad misma y se responde: "como los topos en el sol, nuestros sentidos nos traicionan, y aunque la lengua sea un instrumento incierto y poco fiable, es capaz, no obstante, de unos cuantos momentos milagrosos, de auxiliarnos para ver el mundo" (p. 122).

El autor cita a Chesterton cuando este dijo que, en unas pocas palabras, el lector encuentra todo lo que en realidad está escrito y Manguel agrega que, en esas pocas palabras, "los lectores tratan de enteder, de manera consciente o inconsciente, algo de sus propias circunstancias" (p. 123).

Coincidimos con Manguel en que las palabras son nuestro medio de estar en el mundo y, a través de ellas, podemos identificar nuestra realidad, porque también a través de ellas podemos identificarnos a nosotros mismos.

\section{Patricia María Nigro}

Universidad Autral

pnigro@austral.edu.ar 